\title{
De la razón civilizatoria a las otredades epistémicas: análisis del discurso del desarrollo en América Latina en clave (de)colonial
}

From civilizing reason to epistemic otherness: analysis of the development discourse in Latin America in (de) colonial key

Vanesa Castro

Universidad Nacional de San Juan - Argentina

San Juan, Argentina

vanesa.e88@gmail.com

\section{RESUMEN}

Este artículo analiza las construcciones discursivas en torno a la noción de desarrollo en las políticas que han tenido lugar en el contexto latinoamericano de la segunda mitad del siglo XIX en adelante. Se plantea un análisis crítico de discurso situado históricamente y desde una perspectiva de la genealogía decolonial, revisando los principales modelos de desarrollo territorial y sus discursividades legitimadoras. No se plantea efectuar un análisis meticuloso de la historia de las ideas latinoamericanas acerca del desarrollo, sino resaltar y desglosar las continuidades, diferenciaciones y rupturas discursivas en torno a este relato hegemónico, el cual tiene un potencial performativo de larga data y se nutre de la episteme capitalista, colonial y eurocéntrica cincelada desde el proyecto de la modernidad. Entre las principales conclusiones se destacan, por un lado, la fuerte legitimidad del discurso del desarrollo extractivo-exportador, que se mimetiza entre otras discursividades como la del del desarrollo sostenible, la cual a pesar de plantear una propuesta superadora, termina por (re)abonar la articulación geopolítica de los territorios en tanto centros y periferias, ratifica al modelo mercado-céntrico y abre espacio para una nueva colonialidad global sobre los territorios subalternos y sobre los bienes comunes. Por otro lado, es posible registrar la apertura a propuestas o discursividades disonantes a las hegemónicas, que emergen de las bases sociales, comunitarias y de la academia decolonial; y dislocan aseveraciones, concepciones e interpretaciones "otras" sobre la relación entre desarrollo y territorio y, en última instancia, configuran expresiones emancipatorias y prácticas decoloniales para una sociedad post-capitalista.

Palabras clave: Desarrollo; Decolonial; Discurso; América Latina; Territorio

\begin{abstract}
This article analyzes the discursive constructions on the concept of development in Latin American politics from the second half of the 19th century onwards. The main models of territorial development and their legitimizing discursivities are studied from the perspective of critical discourse analysis, historically situated, and from the decolonial genealogy. It is not a meticulous study of the history of Latin American ideas about development, but rather it is intended to highlight and disaggregate the continuities, differentiation, and ruptures discursive of this hegemonic narrative, which has performative potential and is based on the capitalist, colonial and eurocentric episteme. The main conclusions indicate, on the one hand, the strong legitimacy of the discourse of extractive-exporter development, which is mimicked among other discourse such as that of sustainable development. Despite proposing an overcoming proposal, sustainable development ends up reaffirming the geopolitical articulation of the territories as centers and peripheries, ratifies the market-centric model, and opens space for new global coloniality on subaltern territories and on common goods. On the other hand, there are proposals or discursivities different from the hegemonic ones, which emerge from the social and community bases and from the decolonial academy; and they dislocate "other" assertions, conceptions, and interpretations about the relationship between development and territory and, ultimately, configure emancipatory expressions and decolonial practices for a post-capitalist society.
\end{abstract}

Keywords: Development; Decolonial; Discourse; Latin America; Territory 


\section{INTRODUCCIÓN}

El discurso del desarrollo continúa siendo la narrativa suprema en nombre de la cual se justifican y se legitiman diversas políticas que promueven la acumulación económica y el avance sobre los territorios, al menos en buena parte América Latina, más allá de cualquier modelo político más o menos democrático (Rodríguez \& Govea, 2006). Esta suerte panacea universal se ha instaurado como marcador económico desde hace al menos unos 70 años. Durante las últimas tres décadas se comenzó a discutir sobre el discurso del desarrollo sostenible (desde el informe de Brundtland), como horizonte para direccionar el diseño de políticas públicas destinadas a mejorar las condiciones de desigualdad social, económica y el deterioro ambiental, entre las diversas regiones del mundo. Esto indica que, aunque parezca un discurso en apariencia desgastado dado el fracaso de sus promesas de prosperidad para las regiones periféricas, la multiplicidad cuestionamientos que ha despertado, la profundización de las desigualdades sociales, y las consecuencias desbastadoras para la salud e integridad de todas las especies y los ecosistemas, lejos se encuentra de su senectud.

Interesa abordar la materialidad del discurso del desarrollo ya que con frecuencia su interpretación menos habitual es reconocer que por medio de ella se transparenta un nuevo orden colonial y global para la región latinoamericana, escenario que encuentra sus aposentos en el orden económico mundial ya establecido, denominado por Ramón Grosfoguel (2006) como sistema mundo moderno, colonial y patriarcal. En línea con lo que expone Santiago Castro-Gómez, las nuevas discursividades del desarrollo (como la del desarrollo sostenible, por ejemplo) robustecen, en clave posmoderna, las dicotomías y jerarquías modernocoloniales en relación al conocimiento (Valiente, 2014). En la actualidad, se asiste a la ratificación del modelo de desarrollo neoliberal mercado-céntrico cuya expresión medular es la transformación glocal de los territorios a través de políticas que retan la (sobre)explotación de la naturaleza. Al respecto se puede considerar la cartera de megaproyectos de la Iniciativa para la integración de la Infraestructura Regional Sudamericana (IIRSA), la cual desde el año 2000 promueve la apertura de nuevos canales de comunicación (terrestres, aéreos y marítimos), que faciliten el flujo de energías, de materias primas y de servicios a fin de que los territorios comprendidos sean más competitivos. Si bien la promoción de la integración territorial y el desarrollo local puede acarrear nuevos beneficios para las poblaciones afectadas por la IIRSA, lo cierto es que las estrategias que se priorizan amenazan con exacerbar la disputa por los bienes comunes, la sustitución de prácticas productivas que sean funcionales a las necesidades de capitales trasnacionales, la dependencia territorial y, en última instancia, acentuar la desigualdad social imperante.

De acuerdo con esta perspectiva, se torna imperioso avanzar hacia la segunda descolonización, o decolonialidad como sostienen Santiago Castro-Gómez y Ramón Grosfoguel (2007, p. 17), cuya principal orientación es avanzar en la resignificación de las múltiples relaciones heterárquicas en torno a las construcciones raciales, étnicas, sexuales, epistémicas, económicas y de género, las cuales están incólumes desde la primera descolonización, que tuvo lugar en los siglos XIX y XX. No obstante, este proceso de decolonialidad constituye una apuesta a largo plazo que no puede ser reducida a un fenómeno jurídicopolítico ni de praxis asilada.

Es preciso reconocer que una de las principales manifestaciones de la colonialidad es la colonialidad del saber, dado que se sigue pensando e interpretando la realidad social y produciendo conocimiento desde el ethos eurocentrista. En este sentido, el artículo pretende, en primer lugar, auspiciar una lectura crítica comprensiva sobre el horizonte gnoseológico que da fundamento y sustento al discurso hegemónico del desarrollo, el cual hunde sus raíces en el poder y saber colonial (León, 2005). Luego se rastrean y analizan, en clave histórica, las principales corrientes de desarrollo y sus correspondientes argumentaciones discursivas, que han tenido lugar después de la segunda guerra mundial y que fueron traduciéndose en acciones políticas en la región latinoamericana para promover el desarrollo y a integración territorial. En síntesis, se identifica, en primer lugar, a la corriente discursiva de corte ortodoxo-liberal, dentro de la cual se encuentran las teorías de la modernización y las neoliberales. En segundo lugar, se analiza la corriente heterodoxa constituida por las teorías estructuralistas y neo-marxistas. En tercer lugar, aparece el discurso y proyecto neoliberal. Por último, se encuentran las discursividades alternativas, contrahegemónicas y contraculturales, donde se ubican las teorías del postdesarrollo, la ética del cuidado, la economía social 
y solidaria, el Buen Vivir y el postextractvismo, entre otras perspectivas y movimientos que se surgen a principios del presente siglo en América del Sur (Putero, Rodriguez, \& Miceli, 2015) Esta línea se inscribe en la discusión vigente y activa en las ciencias sociales enmarcadas en el giro decolonial, desde el cual se plantea la imperiosa necesidad de llevar adelante la desconstrucción y descolonización de la hegemonía occidental.

Los interrogantes que vertebran este trabajo son conocer: ¿Cómo se explica la hegemonía del discurso del desarrollo desde una perspectiva histórica y decolonial? ¿Qué huellas epistémicas y herencias de la colonialidad del saber es posible identificar en los diferentes modelos y discursos del desarrollo? ¿Cuáles son las alternativas discursivas que tensionan formas de ser/pensar/hacer el desarrollo desde una posición contra hegemónica y contracultural? ¿Es posible vertebrar desde estas perspectivas algunas prácticas decoloniales?

\section{METODOLOGÍA}

Se emplea el enfoque del análisis crítico del discurso para reconstruir las diferentes corrientes de desarrollo, y sus argumentaciones discursivas, situado históricamente y desde la perspectiva de la genealogía decolonial (Beltrán-Barrera, 2019). Se revisan y analizan diversas fuentes autorales que han dado sustento o bien cuestionado la noción de desarrollo en América Latina.

Por un lado, el análisis crítico del discurso permite echar luz sobre la influencia y (super)pervivencia que tiene, en este caso, el discurso del desarrollo en las formas del pensar-hacer latinoamericano desde el entramado capitalista-colonial-eurocéntrico y la potestad que sigue teniendo en la legitimación de sistemas de valores -sociales y políticos-, en general (van Dijk, 2009), y en el impulso a políticas públicas, en particular. En otros términos, permite una aproximación a la representación discursiva del desarrollo vinculada a ideologías hegemónicas. Desde esta perspectiva se considera que el lenguaje construye la realidad social e interactúa con la cultura (Zimmermann, 2014).

Por otro lado, desde la genealogía decolonial se presenta al sistema-mundo moderno, como macroestructura inherente a la colonialidad del poder. Se despliega un análisis situado e histórico de los diseños globales que tienen incidencia en la región y sus representaciones discursivas a nivel de los estados y a nivel de la región latinoamericana, que han sido andamiaje de las estructuras de poder sostenidas por más de 500 años. La genealogía decolonial, desde una perspectiva foucaultiana descentrada, permite comprender las dinámicas presentes de la política global mediante el análisis de sus discursos y prácticas políticas en torno al desarrollo, en tanto mito fundante. En Foucault, la genealogía constituye una analítica del poder, por medio de un método que permite trazar la historia a fin de conocer cómo el saber y las grandes verdades gravitan en relación a mecanismos históricos de poder (Hernández González \& Rodríguez Mora, 2012, p. 189).

Finalmente, la genealogía decolonial, concebida como una inflexión epistémica, permite descifrar y reactivar aquellos conocimientos ocultados e invisibilizados por un dispositivo hegemónico de producción de saber del desarrollo y por la expansión de la modernidad colonial (Sánchez Antonio, 2020). En este sentido, la noción de "saberes sometidos" trabajada por Foucault (1992) es medular, quien los define como aquellos saberes subyugados a los contenidos históricos y que han sido sepultados, soterrados y enmascarados por ser considerados ingenuos, incompetentes, insuficientemente elaborados, incapaces de unanimidad, inferiores jerárquicamente al nivel de conocimiento o de la cientificidad exigida.

\section{DESARROLLO}

\subsection{Hacia una genealogía del desarrollo en clave (de)colonial: un marco para el análisis de las discursividades}

El capitalismo comenzó a desarrollarse como un nuevo sistema social en Europa hace cinco siglos, a partir de la creación "de un comercio y un mercado mundialmente expansivos" (Marx, 1959, p. 146), a medida que el viejo orden feudal decaía y entraba en proceso de extinción. De esta manera, se constituyó en 
la primera forma de sociedad capaz de incorporar todas las otras formas en una sola formación social (Robinson, 2013), dando origen a lo que Immanuel Wallerstein (1974) designa una "economía-mundo", dentro de un "sistema mundo moderno". Con esta noción, Wallerstein trascendió los estudios de los estado-nación que los abordaban de forma individual y apartada. Su propuesta parte por examinar la historia y los orígenes del capitalismo, desde el radar global, considerando sistema-mundo y su propuesta de estructura económica.

La incorporación de América en los intercambios mercantiles a esta nueva economía-mundo articuló unos procesos de producción, unas cadenas mercantiles y una división internacional del trabajo a nivel global (Navarrete Saavedra, 2010). La economización de las nuevas sociedades americanas colonizadas es justificada y promovida desde la narrativa promesante del orden, civilización y progreso. El proyecto de modernidad fue inspirado por los filósofos del iluminismo en el siglo XVIII, basados en la promoción de una ciencia objetiva, una moral universal, y una ley y un arte autónomos y regulados por lógicas propias (Habermas, 1989). Este proyecto se gestó simultáneamente en Europa y en las Américas, instituyéndose bajo una condición de colonialidad, donde el orden social europeo se estableció como la frontera de la civilización (Santos \& Meneses, 2014), comenzando a operar lo que Anibal Quijano (2000) denomina una colonialidad del poder basada en un modelo hegemónico global de poder - el capitalismo mundial colonial/ moderno.

La colonialidad del poder se asienta en relaciones de poder y de saber que diseñan e institucionalizan fronteras no solo territoriales sino, sobre todo, de categorización de personas y divisiones ontológicas (Mignolo \& Gómez, 2015). Esta fronterización y operación clasificatoria, al decir Walter Mignolo (2001, p. 24), estructuró una epistemología de doble cara (una visible y otra invisible) y una forma de entender el mundo detentada desde un lugar geopolítico de superioridad. La emergencia del sistema-mundo moderno se puede explicar a partir de la interrelación de los siguientes fenómenos sintetizados en la llustración 1.

Ilustración 1. Fenómenos del sistema-mundo moderno colonial

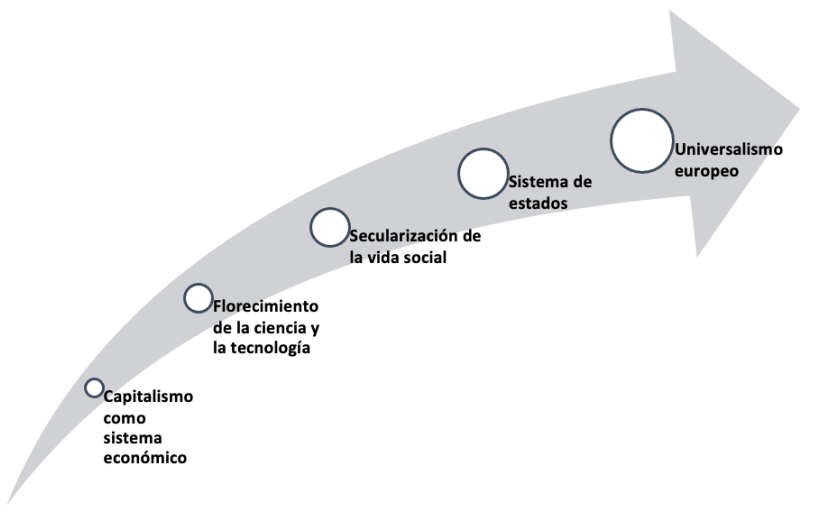

Fuente. Elaboración propia a partir de Restrepo \& Rojas, 2010.

La colonialidad articula, al menos, tres líneas de clasificación social: el trabajo, la raza y el género, de acuerdo con las necesidades del capital y para el beneficio de los hombres blancos europeos (Escobar, 2003; Restrepo \& Rojas, 2010). Edgardo Lander (2000), ha profundizado en la dimensión epistémica de la colonialidad del poder bajo la noción de colonialidad del saber, relacionada con los discursos a través de los cuales se comprende al mundo social, al clasismo, el racismo, el sexismo y su interseccionalidad. Estos discursos colonizan el ser, llevando a actuar bajo patrones capitalistas, racistas y sexistas de identificación -que se reproducen consciente o inconscientemente-, limitando la acción, es decir, la colonialidad del poder.

Hacia finales de los años noventa, Walter Mignolo repara en otras de las dimensiones de la colonialidad: la colonialidad del ser, inspirado en el pensamiento de Enrique Dussel, quien advirtió la conexión entre el Ser y la historia de las empresas coloniales. La colonialidad del ser se refiere a "la experiencia vivida de la colonización y de su impacto en el lenguaje" (Maldonado-Torres, 2007, p. 103). En resumen, 
...la colonialidad es un fenómeno histórico muy complejo que opera a través de una manifestación de jerarquías (raciales, territoriales y epistémicas) que permiten la reproducción del patrón de dominación. Esas jerarquías naturalizadas se conforman a partir de la voz de quienes detentan el poder, lo cual se ve reflejado en diferentes espacios y en los discursos de distintos actores. (Blanc \& García Ríos, 2016, p. 141)

La siguiente figura sintetiza las tres dimensiones de la colonialidad según los autores desarrollados.

Ilustración 2. Dimensiones de la colonialidad

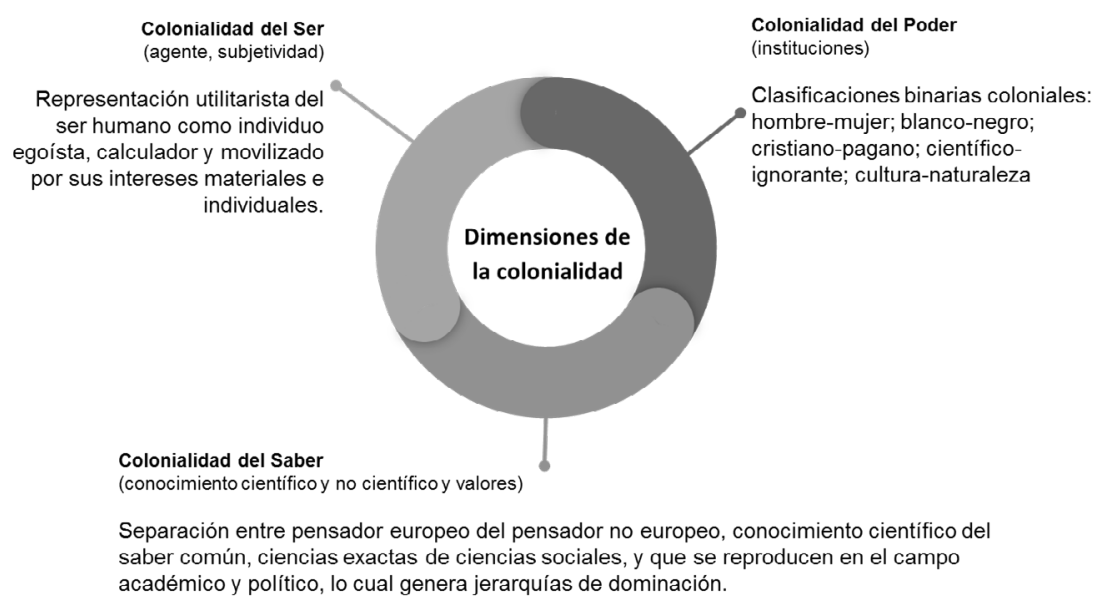

Fuente. Elaboración propia a partir de Martins, 2015.

Este patrón colonial de relacionamiento ha demostrado ser más duradero y estable que el propio colonialismo (Cano Aguilón, 2013). La narrativa de la modernidad y del pensamiento ilustrado se propagó por América, pasando de esgrimir la misión evangelizadora en el siglo XVI, a la civilizadora, entre los siglos XVII y XIX (Shifres \& Rosabal-Coto, 2017). Más tarde, durante el siglo XX, los países más industrializados que controlaban la economía por entonces siguieron imponiendo la ontología colonial en la forma de un relato del progreso. Al interior de nuestro continente, los valores de ese paradigma colonial han sido incorporados y reproducidos con naturalidad por el lenguaje del pensamiento económico convencional y por las sociedades poscoloniales, legitimando un sistema desigual de relaciones de poder entre las poblaciones. En este cuadro las historias de los colonizados pasaron a ser contadas por los hombres letrados, pasando a conformarse en la versión oficial y universal.

Siguiendo esta línea, se instaura en el siglo XIX en Occidente la noción de desarrollo a partir de que la sociedad liberal industrial se constituyera no sólo en el orden social deseable, sino en el único posible (Gómez Hernández, 2014). Desde la crítica decolonial, el discurso del desarrollo representa una de las últimas expresiones que materializan las creencias de la modernidad en el presente. Ahora bien ¿Por qué se arguye que en el discurso del desarrollo opera la matriz colonial? Para responder a ello se sostiene que, aunque la colonialidad emerge con la colonización y la conquista del Atlántico iniciada hace cinco siglos por el proyecto de la modernidad, sus lógicas continúan revelándose en la organización de las nuevas naciones-estado, y alrededor de las estructuras materiales y simbólicas impuestas en el siglo XXI (Robinson, 2013). En la llustración 3, se sintetizan los ciclos progresivos del capitalismo y los hilos discursivos que han acompañado cada periodo, para la justificación de su hegemonía. 
Ilustración 3. Periodos del capitalismo y sus respectivos discursos

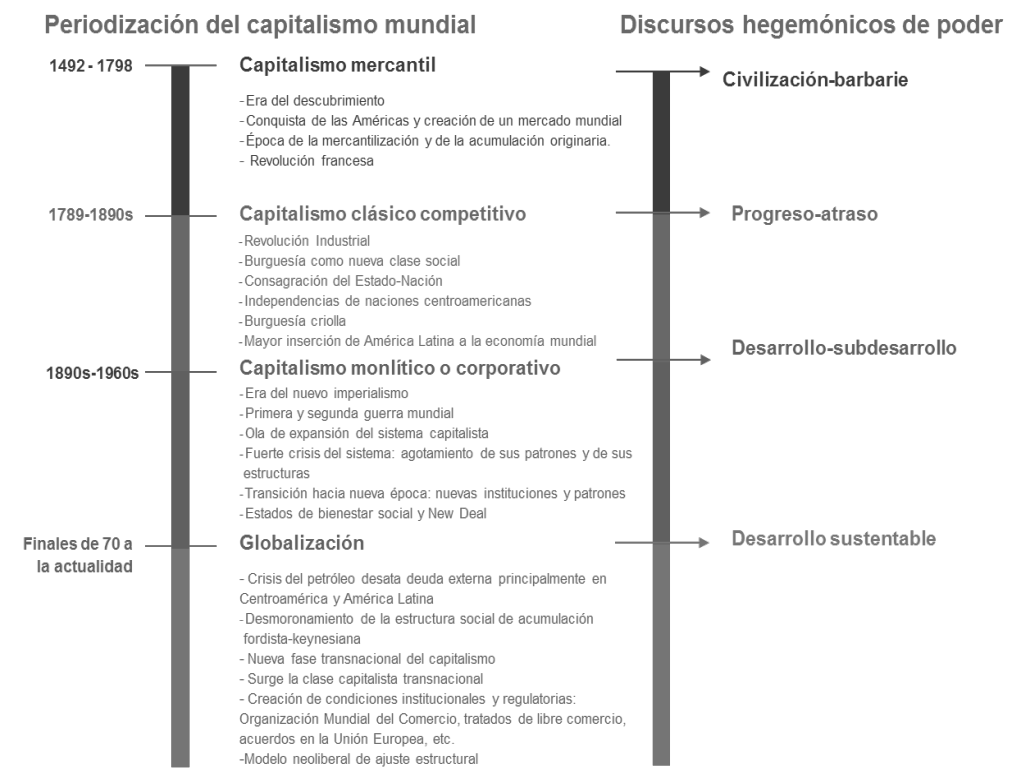

Fuente: elaboración propia a partir de Robinson, 2013.

La colonialidad del saber es el andamiaje epistémico del discurso del desarrollo , el cual desde "la segunda mitad del siglo XX encarnó la visión evolucionista y teleológica de discursos anteriores como el civilización, progreso y modernización" (Gómez-Quintero, 2010, p. 99). Una cuestión no mencionada hasta acá, pero que resulta relevante de resaltar, es que a partir de estas construcciones epistemológicas se ha naturalizado el dominio sobre la naturaleza incluso estableciendo una escisión con aquello que se entiende por cultura. La marginalidad ejercida sobre la naturaleza, o biocolonialidad, en el presente se expresa a través del discurso del "desarrollo sostenible" que paradójicamente al tiempo que se ha apropiado del relato proteccionista del medio ambiente y promueve políticas para la superación de la pobreza, la reducción de la desigualdad social, el acceso a la justicia, la infraestructura, etc. también justifica intervenciones militares (Garduño Oropeza \& Stingl, 2017) y afianza el nuevo proceso de capitalización de la naturaleza o reverdecimiento de la economía, donde se tornan elementales la planificación de la realidad social, la investigación y aplicación del conocimiento técnico- científico para dar cauce al proyecto neocolonial(Quijano Valencia et al., 2007, p. 12).

La colonialidad ha cristalizado su esencia performativa, solo que a diferencia de los siglos anteriores actualmente se asiste, más bien, a la transición del colonialismo moderno a la colonialidad global, en el que se han superado las formas de dominación desplegadas por la modernidad bajo mecanismos coercitivos, pero no así la estructura de las relaciones centro-periferia a escala mundial. De esta manera lo que se establece es una hegemonía de carácter ideológico (Castro-Gómez \& Grosfoguel, 2007; Castro Orellana, 2014). Probablemente, la característica más fuerte del eurocentrismo ha sido el "modo de imponer sobre los dominados un espejo distorsionante que les obligará a verse desde entonces, con los ojos del dominador, encubriendo sus perspectivas históricas y culturales autónomas" (Quintero, 2014, p. 70). .

\subsection{Historia de una invención: (des)entramando los discursos del desarrollo en América Latina.}

Registrar el desplazamiento epistémico desde el mediterráneo hacia el atlántico como escenario del intercambio mercantil a una escala global a partir siglo XVI y como horizonte de realización para los pueblos latinoamericanos, es fundamental para debatir y desentrañar la concepción eurocéntrica y colonial (Mignolo, 2003 citado por Navarrete Saavedra, 2010, p. 27) del actual discurso del desarrollo. En su constitución fue clave el advenimiento de la modernidad puesto que representó la transformación -paulatina pero radical- de las estructuras intersubjetivas que le precedieron, y la formación de un singular modelo de racionalidad que gradualmente fue incidiendo en la totalidad de la población global (Quintero, 2013). 
Para dimensionar las significaciones e implicancias del discurso del desarrollo desde siglo XIX en adelante, es preciso considerar que la colonización ha cincelado durante mucho tiempo un modelo de racionalidad y de evolución de las sociedades coloniales y poscoloniales de acuerdo con los cánones de las potencias que dirigían el sistema económico mundial. Las diversas negociaciones como, la firma del Tratado de Tordesillas por parte de España (Castilla) y Portugal en 1494, el Tratado de San Idelfonso $1^{\circ}$ de octubre de 1777, el Tratado de Madrid el 13 de enero de 1750, entre otros, por parte de los Estados absolutistas constituyeron acontecimientos importantes no sólo en la inscripción del orden mercantilista (Benites, 2007), sino que además sirvieron de base para la conformación de espacios geopolíticos subordinantes.

De la misma manera, en este proceso de dominación también fue primordial la profundización de una economía de mercado de los territorios colonizados basada en la especialización de los productos que estos podían producir y que demandaban las metrópolis europeas. Como corolario, se alumbró un nuevo tipo de sociedad de características similares en las sociedades colonizadas como Asia, América Latina y África (a pesar de la profunda diferencia de origen de cada una), dando cabida, por un lado, a un sector de la población que vivía del régimen de explotación en función de la metrópolis, mientras que otro, seguía viviendo en régimen de economías tradicionales. Esta herencia del colonialismo, tanto en la división territorial a través de tratados y la formación de estos dos sectores socioeconómicos en países colonizados, sentaron las bases sobre las que se han articulado las economías de los países (Colomo Ugarte, 2004), que luego se llamarían subdesarrollados.

En el periodo que trascurre desde la segunda guerra mundial hasta la crisis del petróleo (1945-1973), diversas corrientes comienzan a discutir en profundidad el desarrollo como paradigma económico. Aquí es relevante destacar dos hechos que contribuyeron a erigir la idea hegemónica de desarrollo y a establecer un nuevo orden territorial mundial: el tratado de Postdam (1945) y el discurso del presidente estadounidense Harry Truman (1949).

El tratado de Postdam marcó el inicio del nuevo orden internacional en el que las potencias vencedoras de la segunda guerra mundial, se repartieron las áreas de influencia y consensuaron las reglas básicas de funcionamiento en el ámbito internacional. Allí nace la Organización de las Naciones Unidas en 1945. Por su parte, el discurso del presidente de Estados Unidos, Harry Truman, pronunciado el 20 de enero de 1949, marcó un hito puesto que "legitima la idea contemporánea de desarrollo"(Cuestas-Caza, 2019, p. 53),como horizonte histórico y universal para los países de América Latina. Este discurso no solo subrayó los puntos esenciales de su plan económico como seguir con el Plan Marshall (1948-1952), apoyar la constitución de las Naciones Unidas, y crear una organización común de defensa que pocos meses después se conocería como la OTAN (Roig, 2008), sino que además se lo reconoce como el hecho en que se menciona por primera vez el término "subdesarrollo". Finalizado el enfrentamiento se vivía un clima de grandes esperanzas, las naciones aliadas vencedoras establecieron los acuerdos de Bretton Woods (New Hampshire, EEUU, en 1944), como un marco general que llevaron a considerar la ayuda extranjera como una llave para el desarrollo económico. Estados Unidos pasa a tener un lugar medular en el sistema económico mundial y los países europeos, latinoamericanos, africanos y asiáticos, pasan a disputar sus posiciones en ese nuevo panorama. Resulta llamativo que paradójicamente valores que enarbolan las instituciones que emergen desde Breton Woods justifican la,

...estructura que se viene a legitimar como extraestatal, y que literalmente es ajena en cuanto su consistencia discursiva y mandatos de las poblaciones para las cuales dice estar al servicio, en el tanto se plantean desde el afuera, mientras la efectividad de sus poderes y discursos reside en lo externo y por tanto ajeno. (Gómez Ordoñez, 2011, p. 128)

En esa época hablar de desarrollo rebosaba de promesas, de metas a alcanzar, obstáculos a superar, de imágenes que conducían a imitar los logros de sociedades avanzadas. Se propuso integrar a los territorios subdesarrollados: Asia, África y América Latina (Manzanal, 2012), de modo que alcanzaran el esquema de los países del desarrollados. Para ello, se llevaron adelante procesos de transformación de valores y de subjetivación en los que además de considerar el factor económico para el crecimiento, se promovió 
la modernización cultural, social y política de los países considerados subdesarrollados, definidos según patrones occidentales. Esto contribuyó a que el discurso del desarrollo se complejice y se condense como ideología. En este punto Milton Santos (2003), sostiene que el término subdesarrollo fue discutido, condenado y definido en un tiempo récord, tanto que los hombres del mundo más pobre se olvidaron de que pertenecían a un mundo explotado.

En esta arena ideológica convergen los teóricos pioneros y conservadores de la economía marcados por la visión homogénea, universal y unilineal del desarrollo. Esta visión estuvo cimentada por economistas neoclásicos como Alfred Marshall, Leon Walras, Vilfredo Pareto y Arthut Pigou (Zapata \& Chávez, 2018), cuyas elucubraciones teóricas más relevantes se justifican desde la teoría o la escuela de la modernización (Lewis, Rostow, Huntington, Parsons). Su planteamiento central era que los países subdesarrollados encontrarían el "motor" del desarrollo en la acumulación de capital, la industrialización deliberada, la planeación del desarrollo y la ayuda externa (Escobar, 2008). Para ellos el Estado, al igual que la industrialización y el comercio internacional, debía tener relevancia en la mejora de las dinámicas del mercado, en el ingreso de los ciudadanos y de sus condiciones de vida.

Para implementar este plan y superar la pobreza, los países desarrollados otorgaron préstamos y brindaron apoyo a los movimientos reformistas para evitar la deriva del sistema capitalista, de los países subdesarrollados. Sin embargo, pese a los apoyos brindados, las relaciones comerciales con los países surgidos de la descolonización no podían cambiar la estructura productiva fundamentada en siglos de existencia. Por lo que siguieron fundamentándose principalmente en el intercambio de tecnología por materias primas (Colomo Ugarte, 2004).

Así es como América Latina partió de un modelo de desarrollo basado en sustituir las importaciones industriales por producciones nacionales propias a partir de las rentas generadas por las exportaciones de productos primarios, la llamada Industrialización por Sustitución de Importaciones (ISI), beneficiándose de la fase expansiva de la economía mundial después de la segunda guerra mundial. Por su parte, las élites locales de los países denominados subdesarrollados cumplieron un rol central adoptando este modelo, ya que se ajustaba a su objetivo de modernización y contribuía a reforzar su poder local (Álvarez, 2013).

Entre ciertas dificultades, estos procesos de industrialización fueron relativamente exitosos, sobre todo en los países más grandes del continente: Brasil, México y Argentina (Lander, 2014, p. 2). No obstante, como sostiene el autor Colomo Ugarte (2004) si bien en los países subdesarrollados se evidenció hubo intentos para gestar un desarrollo autocentrado y estructurado o de explotación de las supuestas ventajas comparativas en el mercado internacional, el discurso del desarrollo circunscrito al marco nacional de las elites políticas de estos países, constituye "el discurso de perpetuar la cárcel de los pobres del mundo", ya que en el fondo estos discursos nacionalistas, carecían de soluciones eficaces a los profundos desequilibrios socioeconómicos.

Hacia finales de los 6o, este modelo industrializador mostró su debilidad expresada en la rigidez de los mercados internos de cada país. En esos años la CEPAL (Comisión Económica para América Latina) planteó la necesidad de una cooperación económica entre países latinoamericanos. Los cepalinos abrieron camino a nuevas olas de pensamiento crítico: las teorías de la dependencia, la tesis de la colonialidad interna y las ideas teológicas de la liberación, las cuales contribuyeron a ampliar la crítica postcolonial al considerar otros elementos no-económicos como los morales, políticos, estéticos, culturales y religiosos (Martins, 2015).

\subsection{La línea heterodoxa: primeras (de)construcciones latinoamericanas}

El enfoque estructuralista o desarrollista derivado del trabajo germinal de la CEPAL y cuya profundización viene de la mano del argentino Raúl Prebisch, constituyó una de las primeras teorías económicas heterodoxas de origen latinoamericano. Su planteamiento fundamental es que los problemas que padece la región son de carácter estructural, al explicitar que "la periferia" la constituyen aquellas regiones cuya economía está especializada en la producción de materias primas y manufacturas poco elaboradas, con formas de control del trabajo coercitivas y, en general, mal remuneradas. Mientras que, por otro lado, se 
encuentran países con una posición de "centro" que, al concentrar el capital y beneficios de la producción capitalista, ostentan el desarrollo de tecnología, producen manufacturas complejas, compran materias y bienes baratos de la periferia y venden los suyos a altos costes. Son sociedades con altos índices consumo, la forma fundamental de control del trabajo es la relación capital-salario, y en lo político son estadosnación fuertes (Espiñeira González, 2009).

De cara a esa realidad el estructuralismo plantea la necesidad de construir una teoría económica distinta que responda a la lógica de funcionamiento específica de los países periféricos, que corrija sus deformaciones estructurales, que supere el atraso tecnológico, promoviendo un "desarrollo hacia adentro" dirigido hacia el mercado interno, siguiendo las lecciones que había dejado el proceso espontáneo de industrialización que vivió América Latina entre las dos guerras mundiales. Además, enfatizan en la participación del Estado para la instrumentación de políticas, programas y líneas de actuación que transformen las naciones de manera sostenida (Castillo Eslava, 2017), pero que sea respetuoso de la iniciativa privada, que haga de la ISI el eje de un conjunto de reformas estructurales, entre las que se incluían dos planteamientos audaces para la época: la Reforma Agraria y la Integración Latinoamericana.

Los resultados de la implementación de este modelo fueron distintos a lo proyectado dado que se esperaba que la ISI y el desarrollo hacia adentro genere una mayor independencia del comercio exterior, pero como el financiamiento de la ISI dependía de las exportaciones, este hecho sumado al impacto de la crisis determinó una mayor dependencia del comercio exterior. Por otro lado, los estructuralistas pensaron que el traslado de los centros de decisión hacia el interior determinaría la formación de un Estado nacional independiente y de una burguesía nacional. En realidad, en los años 60 y 70 se constató un control creciente del capital extranjero sobre la gran industria e incluso un aprovechamiento de los mercados ampliados de la integración subregional para beneficio de las transnacionales. En cuanto a las consecuencias políticas se esperaba un debilitamiento de las oligarquías tradicionales y un avance de la democracia. En términos generales, lo que ocurrió fue el reemplazo de la vieja estructura representada por líderes populistas, para mayor desgracia, por los regímenes de fuerza y sus dictadores que ensangrentaron a América Latina (Salgado Tamayo, 2014).

Aunque estos planteamientos heterodoxos han cuestionado duramente el paradigma economicista del desarrollo, en el fondo seguían dando sostén al crecimiento económico como expresión de progreso material y le daban un lugar importante industrialización (Gudynas, 2011). Sin embargo, los aportes de este enfoque marcaron un punto de bifurcación respecto a la teoría neoclásica, al demostrar que no es posible un crecimiento equilibrado, sino más bien se comienza a ver la situación latinoamericana como herencia del saqueo colonial y neocolonial de los países desarrollados (Mendiluza Dias \& Jimenez Barrera, 2018). Con este planteo se adelantaron en casi dos décadas a los teóricos del post-desarrollo.

\subsection{La restitución conservadora: el proyecto y el discurso neoliberal}

El proyecto modernizador iniciado en la posguerra se constituyó en la fuerza que dio lugar a la emergencia pensamiento neoliberal. Su matriz de origen se encuentra en los pensadores de la Escuela Austriaca, quienes propusieron una revolución cultural y un "orden económico racional" (Hayek, 1945). En 1938 en el denominado Coloquio de Lippman se establece la necesidad de hacer una revolución cultural que consistía en eliminar al Estado como planificador central y construir un sistema donde primen los intereses individuales.

En 1947, cuando el estado de Bienestar en la Europa de posguerra se impuso como conducta política, Friedrich von Hayek convocó a quienes compartían su orientación ideológica a una reunión en la pequeña estación de Mont Pelerin en Suiza. Entre los participantes estaban no solamente adversarios firmes del Estado de Bienestar europeo, sino también enemigos férreos del New Deal norteamericano como: Ludwing Von Mises, los norteamericanos Milton Friedman y Walter Lippman, los alemanes Walter Eukpen y Ludwig Erhard, el lord británico Karl Popper, entre otros. Así conformaron la famosa Sociedad Mont Pelerin, una especie de franco-masonería neoliberal, con alto nivel de dedicación y organización, con reuniones internacionales cada dos años, las que aún mantienen. Su propósito era combatir el keynesianismo y el solidarismo reinante, y preparar las bases de otro tipo de capitalismo, duro y libre de reglas para el futuro 
(Bergesio \& Fandos, 2009). Esta élite retomó el núcleo duro de las teorías de libre mercado, constituidas por las ideas la absoluta centralidad que debe tener en la economía la propiedad privada y el mecanismo de la competencia como motor de la innovación y prosperidad, convencidos de que "es la sumisión del hombre a las fuerzas impersonales del mercado la que hizo posible en el pasado el desarrollo de una civilización que sin ello no habría podido desarrollarse" (Hayek, 1984). En ese momento se constituyeron,

...una serie de clubes y tanques de pensamiento internacionales, que reúnen a científicos, empresarios, economistas, funcionarios y decididores internacionales con la ambición de resolver los problemas globales de manera interdisciplinar. De tal forma nace el Club of Rome en abril de 1968. (Murillo \& Seoane, 2020, p. 222)

Bajo la dirección de Margareth Thatcher, Inglaterra fue el primer país desarrollado en aplicar el ideario neoliberal a partir de 1979. Le siguió EEUU tras la elección de Ronald Reagan en 1980. Sus planes se basaron en políticas vinculadas a la hegemonía del mercado y al abandono de las políticas del Estado de Bienestar. Hubo reformas tributarias que favorecieron a los actores que detentaban altos ingresos, privatización de las empresas estatales, limitación de la influencia de los sindicatos, y la desregulación de los mercados y de las actividades financieras (Colombo, 2013). A la par, se implementaron políticas de ajuste de restricción de la oferta monetaria y del gasto público, lo cual tuvo como resultado la contracción de la economía y el aumento de las desigualdades y el desempleo (Ferrer, 2008). Consecutivamente, el proyecto neoliberal empezó a imponerse en la mayoría de los países, aunque se tratara de gobiernos socialdemócratas (caso de España, Francia y Portugal). Fueron pocos países desarrollados, como Suecia, Austria y Japón, los que no se acoplaron a las premisas del neoliberalismo (Rojas Villagra, 2011).

En América Latina, la ola neoliberal se desató bajo el recetario del llamado Consenso de Washinton. Se trata de un documento ampliamente difundido en el que, a fines de 1989, el economista norteamericano John Williamson sintetizó las políticas neoliberales y las principales medidas económicas impuestas a los países de América Latina, por los principales organismos multilaterales (FMI, BM y BID), y por Estados Unidos. Las propuestas del decálogo de Williamson, fueron: 1) disciplina fiscal; 2) reordenamiento de las prioridades del gasto público; 3) reforma impositiva; 4) liberalización de las tasas de interés; 5) tipo de cambio competitivo; 6) liberalización del comercio internacional; 7) liberalización para la entrada de Inversión Extrajera Directa; 8) privatizaciones; 9) desregulación, y 10) derechos de propiedad (Bolinaga \& Slipak, 2015).

Entre las experiencias pioneras de la aplicación de este modelo fueron Chile bajo el régimen militar de Pinochet y de Videla en Argentina. En Chile a partir de 1973, en reacción a las políticas socialistas de Salvador Allende se llevaron adelantes privatizaciones, desregulaciones, persecución sindical, desgravación a los sectores de mayores ingresos, entre otras políticas en la misma línea. Por su parte, Bolivia acogió un plan neoliberal a partir de 1985, en respuesta a la hiperinflación que asolaba al país en aquel momento. Pero el diluvio neoliberal, como lo denomina Atilio Borón (2003), recién se consolidó con la elección de Salinas en México en 1988, Menem en Argentina en 1989, Carlos Andrés Pérez en Venezuela y Fujimori en Perú en 1990.

Los Tratados de Libre Comercio (TLC) también constituyeron una materialidad importante en el proceso neoliberal. Estos TLC celebrados entre varios países latinoamericanos (considerados estratégicos) con Estados Unidos y la Unión Europea, buscaban afianzar, diversificar y aumentar las exportaciones, y promover la inversión extranjera directa. Para favorecer los acuerdos se dispusieron a reducir aranceles, fortalecer los derechos de propiedad intelectual (DPI) (sobre la industria farmacéutica, electrónica, audiovisual, de software, sobre componentes de la biodiversidad, material genético), abrir el mercado de las compras gubernamentales y flexibilizar las regulaciones en materia de movimiento de capitales y servicios financieros (Díaz, 2008, p. 18). El siglo XXI nos enfrenta a la disputa por el control del conocimiento (las leyes de patentes y de los DPI), ante la tendencia hacia la concentración global del poder y del conocimiento, y en definitiva hacia el establecimiento de formas posmodernas de colonialidad. 


\section{5 "El desarrollo ha muerto": hilvanado un desarrollo otro}

Sin ánimo de caer en simplificaciones ni clasificaciones triviales se puede señalar, de acuerdo con el recorrido vertido hasta aquí, que el discurso del desarrollo se ha instaurado en un tejido complejo de continuidades y rupturas. En ese entramado es plausible identificar al menos tres corrientes paradigmáticas que han afirmado, renovado o refutado la narrativa idea original de desarrollo. Las mutaciones sufridas por el paradigma del desarrollo a lo largo de la historia constituyen una respuesta al desgaste de la idea-fuerza y las sucesivas crisis del capitalismo. Pero a su vez, su reingeniería se ha traducido en múltiples estrategias para prolongar a las políticas públicas, los planes, programas y proyectos desarrollistas (Cuestas-Caza, 2019).

En este sentido, en primer lugar, se ubica la línea de corte ortodoxo-liberal, dentro de la cual se encuentran las teorías de la modernización y las neoliberales; y la corriente heterodoxa constituida por las teorías estructuralistas y neo-marxistas. Ambas líneas ya desarrolladas hasta aquí. Por último, se encuentran las lentes alternativas, contrahegemónicas o contraculturales donde se ubican las teorías del postdesarrollo, la ética del cuidado, la economía social y solidaria, el Buen Vivir y el Socialismo del siglo XXI, entre otras perspectivas que surgen a principios del presente siglo en América del Sur (Putero, Rodriguez, \& Miceli, 2015). A diferencia de las corrientes anteriores, la línea alternativa y contrahegemónica abandona la visión de desarrollo asociada al progreso como concepción lineal y cuestionan los estándares de consumo que toman como modelo al sistema de vida vigente en las sociedades de los países desarrollados o centrales. Estas epistemologías fronterizas buscar subvertir y/o redefinir el discurso de la modernidad desde cosmologías y las epistemologías de lo subalterno colonizado, y avanzar hacia una lucha por la liberación descolonial y la transformación de las y prácticas socioeconómicas y políticas más allá de las construcciones concepciones impuestas por la modernidad/colonialidad/capitalista euro-norteamericana (Vargas Soler, 2011).

Recuperando la expresión nietzscheana expuesta en el libro "Así habló Zaratustra" se dice que el "desarrollo ha muerto" en el sentido de que las epistemes fronterizas son las primeras en comenzar a deconstruir y develar las contradicciones del paradigma hegemónico del desarrollo y, sobre todo, en acuñar nuevas lecturas, teorías y experiencias que abonan nuevos lenguajes de valoración del desarrollo. Su búsqueda además es establecer otros conceptos civilizatorios, otra manera de no usar la palabra desarrollo, y defender otras relaciones con la Madre Tierra y la naturaleza (García-González, 2011). Su emergencia convoca a estructurar temas, consignas y conceptos límites que operan como marcos de acción colectiva contestataria, liberadores y emancipatorios respecto de la modernidad dominante, y alimentan los debates sobre la salida al extractivismo y una modernidad alternativa (Svampa, 2011). Desde la lectura que aportan, el desarrollo tal y como ha sido revelado no volverá a ser concebido de la misma manera aun cuando preserve su status quo. En alguna medida, estas corrientes constituyen el cimiento desde el que luego se ha nutrido la crítica y episteme decolonial.

En la línea alternativa y contrahegemónica, sobresalen las contribuciones del enfoque del post-desarrollo que devienen de los trabajos del antropólogo Arturo Escobar preocupado por el contexto latinoamericano. Inspirado en Michel Foucault (2002) sobre la dinámica del discurso y del poder en la representación de la realidad social, Escobar sostiene que,

...el desarrollo debe ser visto como un régimen de representación, como una invención que resultó de la historia de la posguerra, y que, desde sus inicios, moldeó ineluctablemente toda posible concepción de la realidad y la acción social de los países que desde entonces se conocen como subdesarrollados (Escobar, 1998, p. 14).

Pensar el desarrollo en términos del discurso permite señalar los dispositivos de poder implícitos en él. El discurso opera sin procedimientos de exclusión que, basados en una voluntad de verdad, determinan lo que resulta normal y anormal, permisible y prohibido o deseado e indeseado al interior de un sistema social. Se presenta como una construcción de saber "verdadero", con lo cual autoriza y fundamenta las prácticas recurrentes en dicho contexto (Garduño Oropeza \& Stingl, 2017; Legoas, 2007; Ruiz-Lurduy et $\mathrm{al}, 2016)$. 
Escobar se centra en los efectos que la deconstrucción del desarrollo tiene en la praxis, esto es, la certeza de que las comunidades y los sujetos son capaces de crear otras formas de desarrollo, de inventar su propio destino y de plantear otros significados y otros objetivos que en términos de modernidad pueden quedar al margen del modelo de desarrollo hegemónico (Ruiz-Lurduy et al., 2016). Según Cuestas-Caza (2019), si bien es cierto que la propuesta del postdesarrollo ha surcado la deconstrucción del metarrelato del desarrollo este no ha llegado a constituirse como la superación del paradigma occidental por cuestiones estructurales.

\subsection{El discurso del desarrollo en el siglo XIX: ¿fantasma de un proyecto inconcluso?}

En el siglo XXI, la colonialidad continúa haciendo eco en la (re)articulación de una cartografía global, que abre nuevos espacios para el vaciamiento, despojo territorial y ampliación de las brechas sociales (Grinberg, 2012). Aun cuando el extractivismo comenzó hace más de 500 años, ni este ni la conquista ni colonización se terminaron con la emancipación a la dominación europea en América Latina (Brand \& Acosta, 2017, p. 72).

La nueva oleada discursiva pone como marcador valorativo nuevamente al desarrollo y crecimiento reafirmando la inevitable inserción de los territorios al capitalismo global. De esta manera, gran parte de la geografía desigual impuesta desde el colonialismo en América Latina está siendo robustecida por medio de tratados regionales de comercio e infraestructura destinados a garantizar el proceso de "acumulación por desposesión" (Harvey, 2004). Estos tratados en su mayoría, sino todos, significan una consolidación de la expansión de las fronteras extractivistas de hiperurbanización, biomercantilización, megainfraestructuras y agroindustria (Cuevas Valenzuela et al., 2018).

Durante la última década, una de las iniciativas que se destacan en el impulso de estos procesos de (des)(re)territorialización y reestructuración territorial en América Latina, es la IIRSA, ya mencionada previamente. Este proyecto ha venido promoviendo, a escala continental, la integración económica y regional mediante el despliegue de una alianza estratégica de megainfraestructuras (vías, puertos, aeropuertos, corredores, etc.) que faciliten la movilidad de materias primas y recursos naturales hacia las hegemonías político-económicas del Asia-Pacífico, en particular China (Madrid et al., 2011). Como bien lo señala Zibechi (2012), por medio de este despliegue técnico se busca vencer las barreras físicas, legales y sociales para el capital, lo que supone rediseñar la geografía, la legislación de los Estados y las relaciones sociales(Quiñones et al., 2019). Pese a que los gobiernos de corte progresista en América Latina rechazan las políticas implementadas por el Consenso de Washington, resulta llamativa la aceptación de este nuevo esquema de vinculación asimétrico que involucra grandes potencias y que tiende a fomentar la reprimarización productiva de la región. Este fenómeno ha sido denominado por Maristela Svampa (2012) como "consenso de los commodities", bajo el cual describe la acentuada praxis de los gobiernos para promover la explotación de sus recursos naturales o bienes comunes, como un instrumento central para su inserción internacional comercial, independientemente de su matiz ideológico.

La pauta de un capitalismo infinito ante un contexto de crisis climática y de un mundo cada vez más desigual, obliga a cuestionar las instituciones democráticas que terminan legitimando la colonialidad sobre los cuerpos, los territorios, la naturaleza y alumbrando políticas de pobreza. Es urgente vislumbrar un horizonte de justicia no solo social, sino también ecológica como se viene señalando desde diversos sectores (Svampa \& Viale, 2020).

\subsection{Hacia las otredades epistémicas: ¿es posible tejer otro desarrollo?}

La respuesta a este interrogante sin dudas es compleja. De cualquier manera, la búsqueda de respuestas y la construcción de salidas se hace imperativa. Como primera cuestión es preciso partir de un diagnóstico común que reconozca que la continua necesidad de incorporar territorios y poblaciones para la explotación son una expresión inherente a las dinámicas constantes de expansión del capitalismo (Quintero, 2013) y no un fenómeno inicial, transitorio y aleatorio. Esto se manifiesta en los múltiples y cada vez más frecuentes colapsos sociales y ambientales, que continúan poniendo de manifiesto que la lógica del crecimiento infinito y el crecimiento individualista son senderos que conducen al desastre (Santos \& Aguiló, 2019). 
Al respecto, no solo la comunidad científica sino, sobre todo, los diversos movimientos y expresiones sociales- asambleas medioambientales, movimientos indígenas y campesinos, militancias feministas y diversidades de género, luchas de trabajadores rurales y urbanos, marchas y reclamos por la precarización laboral, etc.--, están tensionando este modelo al denunciar los abusos del capitalismo avasallante (Svampa, 2011; Escobar, 2011).

De igual modo, en América Latina, se advierte que tanto el giro ecoterritorial de las luchas como las experiencias ligadas con la economía social y el conocimiento ancestral de los pueblos originarios pujan por dotar de espesor al principio del Buen Vivir o la Buena Vida, aun si la opción extractivista es claramente dominante en la región (Svampa, 2017, p. 14).

Esta situación no puede operar como un diagnostico paralizante, sino justamente es perentorio articular alternativas y salidas a este modelo asfixiante y excluyente de desarrollo. En esta dirección, es plausible rastrear respuestas y construir narrativas que se inspiren justamente en esta constelación manifestaciones colectivas que, en líneas generales, proponen "reconstruir la realidad del poder" (Henrique Martins, 2015). De modo esquemático en la llustración 4 se sintetizan algunas de los principales ejes sobre los que diversos pensadores de la decolonialidad se posicionan para avanzar hacia la deconstrucción de las dimensiones de la colonialidad. La propuesta se articula en una suerte de "ejercicios descolonizantes" que, por su naturaleza, se apartan de la colonialidad académica del saber y tienden a confrontar(nos) con la propia colonialidad, la colonialidad del ser (Mignolo \& Gómez, 2015).

Ilustración 4. Propuesta para descolonizar las dimensiones de la colonialidad

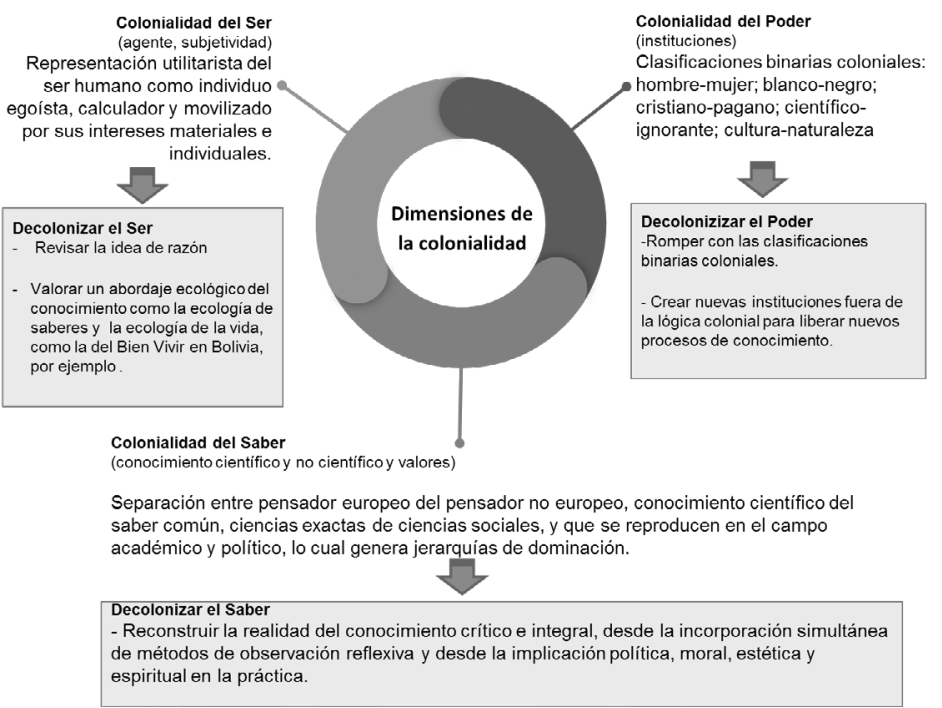

Fuente: elaboración propia a partir de Martins, (2015)

Desde esta perspectiva, la genealogía decolonial no es una praxis esencialista, ni antieuropea ni antioccidente ni antidesarrollo (Grosfoguel, 2006). En este sentido, en la búsqueda por erigir nuevos lenguajes y horizontes, también es central evadir la trampa de la interpretación maniquea que establece una retórica radical antimperialista dicotómica. Como apunta Santiago Castro-Gómez "atacando la lógica del colonialismo no desaparecerá automáticamente la experiencia de la colonialidad”(Hernández González \& Rodríguez Mora, 2012, p. 194). Tampoco se trata de negar el papel de la ciencia y el crecimiento de las sociedades y, en consecuencia, romantizar los "mundos marginales". Esto significaría sucumbir en otro fundamentalismo, que al igual que el fundamentalismo eurocéntrico -que es el más poderoso de cualquier manera-, apuntalaría la premisa de que su propia epistemología es superior, universal y verdadera(Santos \& Meneses, 2014, p.375). La herida colonial no puede ser sanada imponiendo una nueva hegemonía. 
Por el contrario, tejer y activar prácticas decoloniales, ejercicios descolonizantes y narrativas "otras" supone un ejercicio de transmutación de las propias subjetividades colonizadas y de las prácticas políticas individuales y colectivas. En esta dirección es clave observar la labor iniciada y transitada por las comunidades indígenas en América, las posturas post-extractivistas, el pensamiento del post-desarrollo, la teoría del decrecimiento, las cosmovisiones de la cultura andina como el sumak kawsay, los saberes populares y ancestrales en tanto saberes sometidos, los movimientos ambientalistas, la agroecología, el ecofeminismo, los movimientos ecoterritoriales, los movimientos barriales, las economías locales alternativas, las expresiones artísticas contraculturales, entre muchas otras expresiones de la decolonialidad.

\section{CONCLUSIÓN}

De acuerdo, al propósito planteado para este artículo se destacan como conclusiones generales, por un lado, la fuerte legitimidad del discurso del desarrollo extractivo-exportador que se mimetiza entre otras discursividades como la del del desarrollo sostenible o del desarrollo territorial, los cuales a pesar de plantear, en apariencia, una propuesta superadora del paradigma economista clásico, terminan por (re) abonar la concepción dogmática del desarrollo asociado al crecimiento infinito, la articulación geopolítica de los territorios en tanto centros y periferias, ratifican al modelo mercado-céntrico y abren espacio para una nueva colonialidad global sobre los territorios subalternos y sobre los bienes comunes.

Pese a este panorama es posible registrar, la apertura a propuestas o discursividades disonantes a las hegemónicas, que emergen de las bases sociales, comunitarias y de la academia decolonial; las cuales dislocan aseveraciones, concepciones e interpretaciones "otras" sobre la relación entre desarrollo y territorio y, en última instancia, configuran expresiones emancipatorias y prácticas decoloniales para una sociedad post-capitalista.

En relación con esto último, y avizorando el escenario de los últimos años marcado grotescamente por la emergencia climática y la profundización de las brechas sociales, la crisis y el agotamiento de este modelo de sociedad basado en la expoliación de la vida en todas sus expresiones es innegable. Las trayectorias mencionadas en el último apartado (varias de las cuales son consideradas como marginales y subordinadas) constituyen entonces una suerte de bitácora para, por un lado, enarbolar críticas sustanciosas a los límites y la insustentabilidad de los extractivismos capitalistas, a los modelos de consumo imperantes y al rol de la institucionalidad estatal en ese panorama. Por otro lado, y sobre la base de estos cuestionamientos, estas posturas decoloniales pueden inspirar (aunque muchas ya lo hacen, de hecho) a zanjar una agenda de corto, mediano y largo plazo que conduzca a germinar una transición post-capitalista en un entramado de prácticas decoloniales del ser, del saber y del poder. Para lo cual no hay fórmulas ni recetas a priori, sino más bien una diversidad de vías de escape según la realidad heterogénea de cada comunidad, cuidad, microespacio o grupo social. No obstante, en un plano más concreto, estas trayectorias pueden iluminar nuevos conocimientos, reversionar antiguos saberes que alimenten una lectura crítica sobre la crisis civilizatoria, ayudar a replantear y repolitizar la relación con las naturalezas y los bienes materiales, a agenciar otras formas de organización horizontales y de participación ciudadana, a revisar la agendas políticas y económicas globales y locales, a montar una vía hacia soberanía alimentaria de diversidad productiva.

En definitiva, estas experiencias incitan a transpolar y revisar los mecanismos ya instaurados para acceder al conocimiento, a (re)establecer y habitar otros modos de relacionarse y de existir, los cuales puedan estar impresos o emerger de las propias tramas históricas locales y no hegemónicas. Tramas que probablemente evocan una aguerrida, y a menudo silenciosa, expresión de resistencia ante los constantes intentos del colonialismo por desbaratarlas. Desde ese lugar, se considera que es posible (des)montar, (des)activar, (de)construir y (re)significar el desarrollo (si cabe sostener el término), acuñando posicionamientos alternativos al paradigma hegemónico, y apostando hacia una ética biocéntrica que no sea universalizante, jerarquizante, instrumental, utilitarista y antropocéntrica, para auspiciar un mundo pluriverso y pluricultural.

Como desafío para nuevos proyectos políticos y/o de investigación sería importante preguntarse si ¿serán las instituciones actuales las que pueden viabilizar estas salidas o transiciones del proyecto neoliberal predatorio? ¿qué valores es necesario nutrir para una sociedad justa ecológica y socialmente? Si el sistemamundo heredado es desigual ¿es presumible pensar que los dadores de respuesta a esta crisis civilizatoria serán prioritariamente aquellos actores y territorios aventajados? 


\section{REFERENCIAS}

Álvarez, E. (2013). Discursos sobre desarrollo y su influencia en el desarrollo urbano en el Sur global. Urban, 6, 63-76. http://polired.upm.es/index.php/urban/article/view/2054

Beltrán-Barrera, Y.J. (2019). La biocolonialidad: una genealogía decolonial. Nomadas, 50, 77-91. https://doi.org/10.30578/ nomadas.n50a5

Benites, L. F. R. (2007). Cultura e Reversibilidade: breve reflexão sobre a abordagem "inventiva" de Roy Wagner. CAMPOS. Revista de Antropologia Social, 8(2) 117-130. http://doi.org/10.5380/cam.v8i2.11170

Bergesio, L., \& Fandos, C. (2009). Neoliberalismo: ideología y práctica. Su influencia en América Latina de los noventa. En M. Lagos (director), Jujuy bajo el signo neoliberal. Política, economía y cultura en la década de los noventa, (pp. 15-63).

Borón, A. (2003) La sociedad civil después del diluvio neoliberal, En E. Sader y P. Gentilli(comp.), La trama del neoliberalismo: Mercado, Crisis y Exclusión Social, Buenos Aires, CLACSO/Eudeba

Brand, A., \& Acosta, U. (2017). Salidas del laberinto capitalista. Decrecimiento y postextractivismo. Tinta Limón y Fundación Rosa Luxemburgo.

Cano Aguillón, Á. (2013). El plan Colombia: Historia Local/Diseño Global: Análisis del discurso en perspectiva decolonial. [Tesis de doctorado, Universidad Andina Simón Bolívar Sede Ecuador] Repositorio Institucional https://repositorio. uasb.edu.ec/handle/10644/3493

Castillo Eslava, J. F. (2017). La Trampa de la Desigualdad y la Salud Agropecuaria en Latinoamérica: El caso de Nicaragua [Tesis doctoral]. Universidad de Cádiz, Cádiz.

Castro-Gómez, S. \& Grosfoguel, R. (2007). El giro decolonial: Reflexiones para una diversidad epistémica más allá del capitalismo global. Siglo del Hombre Editores.

Castro Orellana, R. (2014). Foucault y el debate postcolonial. Historia de una recepción problemática. Quadranti Rivista Internazionale Di Filosofia Contemporanea, 2(1), 216-249.

Colombo, N. (2013). La integración regional en los discursos políticos oficiales y de la prensa gráfica argentina entre 2001 y 2005 [Tesis doctoral, Universidad Nacional de Córdoba]. Repositorio institucional https://24X7.cl/BWkA

Colomo Ugarte, J. (2004). La formación del espacio económico mundo (Del siglo XVI al siglo XXI). Javier Colomo http://www.javiercolomo.com/index_archivos/Mundo.htm

Cuestas-Caza, J. (2019). El discurso del desarrollo en las políticas públicas: del postdesarrollo a la crítica decolonial. TraHs Números Especiales, 4, 53-67. https://www.unilim.fr/trahs/1561

Cuevas Valenzuela, H., Véjar, D. J., \& Rojas Hernández, J. (Eds.). (2018). América Latina: expansión capitalista, conflictos sociales y ecológicos. RIL editores - Universidad de Concepción.

Díaz, Á. (2008). América Latina y el Caribe: La propiedad intelectual después de los tratados de libre comercio. CEPAL.

Escobar, A. (1998). La Invención del tercer mundo. Construcción y deconstrucción del desarrollo. Norma

Escobar, A. (2003). Mundos y conocimientos de otro modo. El programa de investigación de modernidad/colonialidad latinoamericano. Tabula Rasa, 1, 51-86. https://doi.org/10.25058/20112742.no1.03

Escobar, A. (2008). Territories of difference: place movements life redes. Duke University Press.

Escobar, A. (2011). Ecología Política de la Globalidad y la Diferencia. En H. Alimonda (coord.), La Naturaleza Colonizada, (pp. 61-92). CLACSO.

Espiñeira González, K. R. (2009, diciembre). El Centro y la Periferia. Una reconceptualización desde el pensamiento Descolonial. [Presentación de ponencia] Seminar de Jóvenes Investigadores en Dinámicas Interculturales Barcelona, Barcelona, España.

Ferrer, A. (2008). La economía argentina. Desde sus orígenes hasta principios del siglo XXI. Fondo de Cultura Económica.

Foucault, M. (2002). La arqueología del saber. Siglo XXI Editores.

Foucault, M. (1992). Microfísica del poder. La Piqueta.

García-González, N. (2011). Movimientos sociales y producción de conocimientos: la relevancia de las experiencias de autoformación. (109-122). [Presentación de ponencia] Seminar de Jóvenes Investigadores en Dinámicas Interculturales Barcelona, Barcelona, España.

Garduño Oropeza, G., \& Stingl, R. (2017). Desarrollo, mito y discurso. La configuración del mundo de consumo a través del lenguaje. Revista de Comunicación, 16(2), 214-233. http://doi.org/10.26441/rc16.2-2017-a10

Grinberg, M. (2012). Ecofalacias. El poder trasnacional y la expropiación del discurso verde. Fundación Ross.

Gómez Ordoñez, L. H. (2011). Narrativas del desarrollo: fundamentos, saberes y problemas semánticos analizados desde la Filosofía, el Psicoanálisis y la Teoría Decolonial. [Tesis de maestría, Universidad Nacional de Costa Rica]. Repositorio 
Institucional https://repositorio.una.ac.cr/handle/11056/14985

Gómez-Quintero, J. D. (2010). La colonialidad del ser y del saber: la mitologización del desarrollo en América Latina. El Ágora USB, 10(1), 87-105. https://doi.org/10.21500/16578031.366

Gómez Hernández, E. (2014). Decolonizar el desarrollo. Desde la planeación participativa y la interculturalidad en América Latina. Estacio Editorial.

Grosfoguel, R. (2006). La descolonización de la economía política y los estudios postcoloniales: transmodernidad, pensamiento fronterizo y colonialidad global. Tábula Rasa, (4), 17-48. http://doi.org/10.25058/20112742.245

Gudynas, E. (2011). Debates sobre el desarrollo y sus alternativas en América Latina: Una breve guía heterodoxa. En M. Lang, y D. Mokrani (Comp.), Más allá del desarrollo (pp. 21-53). Abya Yala / Fundación Rosa Luxemburg.

Habermas, J. (1989) Modernidad, un proyecto incompleto. En N. Casullo (Comp.), El debate modernidad posmodernidad (pp. 137-138), Puntosur Editores.

Harvey, D. (2004). El “nuevo” imperialismo: acumulación por desposesión. Socialist register.

Hernández González, F., \& Rodríguez Mora, T. (2012). Genealogía de las herencias coloniales. Entrevista a Santiago Castro-Gómez. Andamios, 9(20), 187-19. https://doi.org/10.29092/uacm.v9i20.376

Hayek, F. (1984) Camino de servidumbre. Fondo de Cultura Económica.

Hernández González, F., \& Rodríguez Mora, T. (2012). Genealogía de las herencias coloniales. Entrevista a Santiago Castro-Gómez. Andamios, Revista de Investigación Social, 9(20), 187. https://doi.org/10.29092/uacm.v9i20.376

Lander, E. (2000). La colonialidad del saber: Eurocentrismo y ciencias sociales. UNESCO-CLACSO.

Lander, E. (2014). El Neoextractivismo como modelo de desarrollo en América Latina y sus contradicciones. Heirinch Boll Stiftung.

León, C. (2005). Hacia una posible superación de la metahistoria de lo latinoamericano. En C. Walsh (Ed.), Pensamiento crítico y matriz (de)colonial: reflexiones latinoamericanas (pp. 111-134). Universidad Andina Simón Bolívar / Ediciones Abya-Yala

Legoas, J. (2007). “Whatchdogs”: ciudadanía y discursos del desarrollo. Tabula Rasa, 7, 17-46.

Navarrete Saavedra, R. (2010). Gobernabilidad neoliberal y movimientos indígenas en América Latina. Polis Revista Latinoamericana, 9(27), 1-16. https://doi.org/10.4067/s0718-65682010000300022

Madrid, C. Hickey, G., \& Bouchard, M. (2011). Strategic environmental assessment effectiveness and the Initiative for the Integration of Regional Infrastructure in South America (IIRSA): A multiple case review. Journal of Environmental Assessment Policy and Management, 13(04), 515-540.

Maldonado-Torres, N. (2007). On the coloniality of being: Contributions to the development of a concept. Cultural studies, 21(2-3), 240-270.

Marx, K. (1959). El Capital, Tomo III. México.

Manzanal, M. (2012). Desarrollo. Una perspectiva crítica desde el análisis del poder y del territorio. Realidad Económica, (283), 17-48. https://24X7.cl/QQPr

Martins, H. (2015). Metodología en los Estudios Post-coloniales y Anti-utilitaristas. En W. Soto Acosta (Ed.). Ciencias Sociales y Relaciones Internacionales: nuevas perspectivas desde América Latina (pp. 113-138) Escuela de Relaciones Internacionales de la Universidad Nacional-CLACSO.

Mendiluza Dias, D. \& Jimenez Barrera, Y. (2018). Estudios del desarrollo social: Cuba y América Latina. Estudios del Desarrollo Social: Cuba y América Latina, 2(1), pp.22-46. http://www.revflacso.uh.cu/index.php/EDS/article/view/71

Meza Monge, N. (2012). Espacios Regionales Fronterizos: Escenarios de Integración. En Revista Integración \& Comercio, 34(16), pp. 25-32.

Mignolo, W. (2003). Historias locales/diseños globales. Ediciones Akal.

Mignolo, W., \& Gómez, P. P. (2015). Trayectorias de re-existencia: ensayos en torno a la colonialidad/decolonialidad del saber, el sentir y el creer. Universidad Distrital Francisco José de Caldas.

Murillo, S., \& Seoane, J. (2020). La potencia de la vida frente a la producción de muerte. El proyecto neoliberal y las resistencias. IEALC, Instituto de Investigaciones Gino Germani.

Putero, L., Rodriguez, S., \& Miceli, F. (2015). América del Sur: crisis mundial, desarrollo y economía social. En M. F. Sañudo (Ed.), Desarrollo. Prácticas y discursos emergentes en América Latina (pp. 279-303), CLACSO.

Quijano, A. (2000). Colonialidad del poder, eurocentrismo y América Latina. En E. Lander (Edit.) La colonialidad del saber: eurocentrismo y ciencias sociales. Perspectivas latinoamericanas, (pp. 122-151). CLACSO.

Quijano, A. (2015). ¿Bien vivir? entre el “desarrollo” y la descolonialidad del poder. Contextualizaciones Latinoamericanas, $122(6), 46-56$. 
Quijano Valencia, O., Juan Camilo, C.-R., Tobar, J., Del Cairo, L., Mario, M., Valencia, F., \& Arteaga, J. (2007). Territorios del saber. Biopolítica y filosofías de vida. Editorial Universidad del Cauca.

Quintero, P. (2014). Desarrollo, modernidad y colonialidad. Revista Antropología Experimental, 13(5), 67-83. https:// revistaselectronicas.ujaen.es/index.php/rae/article/view/1816

Quiñones, P. M., Pinto, A. P., \& Ponce-Hille, M. I. (2019). Discursos geopolíticos de desarrollo y-reestructuración territorial IIRSA en el eje Mercosur-Chile. Dialogo Andino, 59(59), 37-53. https://doi.org/10.4067/So71926812019000200037

Restrepo, E., \& Rojas, A. (2010). Inflexión decolonial: fuentes, conceptos y cuestionamientos. Editorial Universidad del Cauca.

Robinson, W. (2013). Una teoría sobre el capitalismo global: producción, clase y Estado en un mundo transnacional. Siglo XIX Editores.

Rodríguez, I., \& Govea, H. (2013). Reflexiones sobre el discurso del desarrollo en América Latina. Analecta Política, 4(2), 349-370. http://www.redalyc.org/pdf/177/17712202.pdf

Roig, A. (2008). El desarrollo como conflicto institucionalizado. Realidad Económica, (237), 80-92. https://24X7.cl/DzRV

Rojas Villagra, L. (2011). La economía Paraguaya bajo el orden neoliberal. BASE Investigaciones Sociales

Ruiz-Lurduy, R., Rocha-Buelvas, A., Pérez-Hernández, E., \& Córdoba-Sánchez, C. (2016). Desarrollo social y salud pública. Reflexiones en torno a la interculturalidad. Revista Facultad Nacional de Salud Pública, 34(3), 380-388. http://doi.org/10.17533/udea.rfnsp.v34n3a12

Salgado Tamayo, M. (2014). Los paradigmas del desarrollo que mayor influencia han tenido América Latina. Revista Anales, 372(1). 139-163. https://doi.org/10.29166/anales.v1i372.1288

Sánchez Antonio, J. C. (2020). Insubordinación de los saberes sometidos y emergencia de las epistemologías otras. Tabula Rasa, 1(34), 193-223. https://doi.org/10.25058/20112742.n34.10

Santos, B. (2012). De las dualidades a las ecologías. Red boliviana de mujeres transformando la economía.

Santos, B., \& Meneses, M. P. (2014). Epistemologías del Sur (Perspectivas). Ediciones Akal, S.A.

Santos, B., \& Aguiló, A. (2019). Aprendizajes globales. Descolonizar, desmercantilizar y despatriarcalizar desde las epistemologías del sur. Icaria Editorial.

Santos, M. (2004). Territorio e Sociedade, entrevista com Milton Santos. Fundacao Perseu Abramo.

Svampa, M. (2011). Extractivismo neodesarrollista y movimientos sociales ¿Un giro ecoterritorial hacia nuevas alternativas. Más allá del desarrollo. En M. Lang, y D. Mokrani (Comp.), Más allá del desarrollo (pp. 185-218). Abya Yala / Fundación Rosa Luxemburg.

Svampa, M. (2017). La difícil tarea de pensar alternativas al capitalismo. En A. Brand \& U. Acosta, Salidas del laberinto capitalista. Decrecimiento y postextractivismo (pp. 11-18). Tinta Limón y Fundación Rosa Luxemburgo.

Svampa, M., \& Viale, E. (2020). El colapso ecológico ya llegó: Una brújula para salir del (mal) desarrollo. Siglo XXI Editores.

Svampa, M. (2012). Pensar el desarrollo desde América Latina. En G. Massuh (Ed.). Renunciar al bien común: Extractivismo y desarrollo en América Latina. Mardulce.

Shifres, F., \& Rosabal-Coto, G. (2017). Hacia una educación musical decolonial en y desde Latinoamérica. Revista Internacional De Educación Musical, 5, 85-91. http://doi.org/10.12967/riem-2017-5-po85-091

Valiente, S. (2014). Castro-Gómez, Santiago. La poscolonialidad explicada a los niños. Geograficando, 10(1). https:// www.geograficando.fahce.unlp.edu.ar/article/view/GEOv1ono7

Van Dijk, T. (2009). Discurso y poder. Contribuciones a los Estudios Críticos del Discurso. Gedisa.

Vargas Soler, J. C. (2011). La perspectiva decolonial y sus posibles contribuciones a la construcción de Otra economía. La Perspectiva Decolonial Y Sus Posibles Contribuciones a La Construcción de Otra Economía, 3(4), 46-65. http://doi. org/10.4013/1124

Vázquez Barquero, A. (2005). Las nuevas fuerzas del desarrollo. Editorial Antoni Bosch.

Wallerstein, I. (1974). The Modern World-system. Academic Press.

Zapata, J., \& Chávez, M. (2018). Las corrientes ortodoxa y heterodoxa del desarrollo: algunas nociones conceptuales. Opera, 22, 163-183.

Zibechi, R. (2012). Brasil Potencia. Entre la integración regional y un nuevo imperialismo. Editorial Quimantu.

Zimmermann, L. (2014, octubre). Lectura y pensamiento decolonial: aportes del análisis del discurso para la lectura de textos [Presentación de ponencia]. Congreso Nacional Subsede Cátedra Unesco UNR. Santa Fe, Argentina. https://core.ac.uk/download/pdf/61704593.pdf 
AUTORA

Vanesa Castro. Doctoranda del programa de Doctorado en Ciencias Sociales (Universidad Nacional de San Juan) y doctoranda en el programa en Artes y Humanidades (Universidad de Cádiz). Profesora de Planificación Social y Trabajo Final de Investigación en Trabajo Social en la Universidad Nacional de San Juan.

\section{Conflicto de intereses}

La autora declara que no existió conflicto de interés posible.

\section{Financiamiento}

No existió asistencia financiera de partes externas al presente artículo.

\section{Agradecimientos}

\section{$\mathrm{N} / \mathrm{A}$}

Nota

El artículo es producto del proceso de investigación para la tesis doctoral de la autora. 